University of Louisville

ThinkIR: The University of Louisville's Institutional Repository

College of Arts \& Sciences Senior Honors

Theses

College of Arts \& Sciences

$5-2013$

\title{
Injustice and the industrial food system : a structural reconstruction.
}

Alexandra Bree Farrell

University of Louisville

Follow this and additional works at: https://ir.library.louisville.edu/honors

Part of the Philosophy Commons

\section{Recommended Citation}

Farrell, Alexandra Bree, "Injustice and the industrial food system : a structural reconstruction." (2013). College of Arts \& Sciences Senior Honors Theses. Paper 14.

http://doi.org/10.18297/honors/14

This Senior Honors Thesis is brought to you for free and open access by the College of Arts \& Sciences at ThinkIR: The University of Louisville's Institutional Repository. It has been accepted for inclusion in College of Arts \& Sciences Senior Honors Theses by an authorized administrator of ThinkIR: The University of Louisville's Institutional Repository. This title appears here courtesy of the author, who has retained all other copyrights. For more information, please contact thinkir@louisville.edu. 
Injustice and the Industrial Food System:

A Structural Reconstruction

\section{By}

Alexandra Bree Farrell

Submitted in partial fulfillment of the requirements for Graduation summa cum laude and

for Graduation with Honors from the Department of Philosophy

University of Louisville

May, 2013 


\section{Introduction}

In a nation as fortunate as the United States, for millions, food has become a fact of daily life, rather than a cause for controversy or concern. For typical consumers, questions about the sources of their food exist on the periphery-and occasionally, front-and-center when the media choose to highlight them. Most Americans eat their three squares each day and do not deeply consider the chain of events that preceded and produced their meals. In one sense, the methods of food production seem to have been perfected by technology and modernization. Consumers can select from a variety of fresh produce all year, regardless of season, and the aisles of grocery stores are almost absurd in their abundance. Yet recently, social commentators and authors such as Morgan Spurlock, Eric Schlosser, and Michael Pollan have vocalized concerns about the food system, including the nutrition of the food produced by it, its environmental impact, and violations of the rights of workers within the system. The means of food production in this country require careful analysis in order to establish an accurate portrayal of the industrial food system — in light of its productivity and its problems.

By and large, the industrial food system has served its intended purpose. Excluding extreme cases of hunger and “off-the-grid” communes, virtually an entire nation feeds itself by means of the current food system. That is to say, very few individuals derive their food from sources other than traditional grocery stores and restaurants that are constituents of the industrial food system. And Americans typically feed themselves well—in terms of amount, anyway. The average American consumes almost 2,700 calories per day, well above the average caloric need, and the food system even produces an excess_-as many as 3,800 calories per day per person (United States Department of Agriculture). Moreover, on a daily basis, as many as twenty-five 
percent of Americans eat in fast food restaurants, which are arguably one of the most industrial parts of the system and the historical driving force behind it (Freeman).

What exactly is industrial food, and to what does industrial food system refer? Industrial food has come to exist by way of the organizations, cultural norms, and social structures that influence the food choices and habits of hundreds of millions of Americans. In The Omnivore's Dilemma, Michael Pollan defines industrial food as "any food whose provenance is so complex or obscure that it requires expert help to ascertain” (17). Industrial food, of course, is the product of the industrial food system—or the interconnected web of conventional grocery stores, restaurants, advertisers, transporters, distributors, manufacturers, and growers. Agriculture itself is an industry, but the term industrial in this thesis makes reference to the increased mechanization and use of non-human energy in the food system. These trends have significantly altered the means of food production. If one were to sketch the history of the production and consumption of food, one would find a number of historical patterns as well as revolutionary developments. In the early twentieth century, twenty-five percent of Americans lived on farms, and the average farmer produced enough food for approximately 15 people. One hundred years later, there are fewer than two million American farmers, each one of whom can produce enough food for more than 120 people (Pollan 34). Is this efficiency something to be admired? The farm has become a factory, an overwhelmingly productive one. But industrialization and resulting abundance of relatively low-priced food come at a high cost.

There are numerous social, environmental, economic, and health concerns that result from the industrial food system. The problems within the food system that will be discussed in this thesis may be divided into two categories: crises with regard to production and consumption. In terms of production, the current industrial food system has sponsored and relies on the 
establishment of monoculture farms, the use of fossil fuels, antibiotics, hormones, fertilizers, and pesticides, the acceptance of animal cruelty, and the degradation of the lives and the land of the farmer, the industrial worker, and the surrounding community. During its final stage, when the product finally reaches the consumer, further problems result. Concerns related to consumption stem from the poor nutritional value and dubious safety of the food produced by the industrial food system, and the low price of industrial food fails to take into account its true cost to society.

These issues are distressing for a number of reasons. Actors within the industrial food system are presented with a dilemma: eating, an activity so basic and a need so fundamental, generates unintended consequences. The vast majority of Americans depends on and thus reinforces the food system as an institution. The average individual cannot opt out; that is, if a consumer no longer wants to eat industrial food, his or her alternatives will be limited, and in most cases impossible, given the lack of other viable food systems. According to Article 25 of the Universal Declaration of Human Rights, adopted by the United Nations on December 10, 1948, the right to a decent standard of living, including access to food, is a basic human right (United Nations). Human survival, although fortunately far from the minds of many privileged Americans, is intimately bound with the current food system. The public depends on it so intimately to fulfill basic needs—and despite its flaws, it does. But this reliance should give rise to wariness: we can accept our dependence on the food system, but we must also take responsibility for its outcomes, since we derive benefit from it and support it with our consumption.

This thesis endeavors to show that an individualistic model, that by which the general public understands the industrial food system and its consequences, is inadequate to explain and remedy food system problems. This perspective views problems as personal and atomistic, the 
latter of which means that problems are believed to exist independently from other entities and factors. In general, such discourse about the food system centers on individual human agents. The proximity and apparent strict causality between the actor and the seemingly individual problem allow the public to lay blame on the allegedly guilty actor. When concerns do arise, responsibility is assigned to individuals who are assumed to have been acting in their own capacities. Problems are isolated and diagnosed individually, without reference to potentially related factors. It will be shown that this model offers only an incomplete understanding, as it fails to grasp the full depth of the problems within the industrial food system. Proponents of the individualistic model ultimately fail to contribute to the discussion in a meaningful way.

As a result, the analysis of the food system by means of the individualistic model will be rejected in favor of the structural model. From a structural perspective, problems within the food system will be viewed holistically and as instances of structural injustice. The work of social theorist Iris Marion Young will be fundamental to the development of this thesis, as her writings on structural injustice and the resulting notion of responsibility can be applied in a novel way to the industrial food system. Insofar as Young's theories are grounded in injustices distinct from those within the industrial food system, her model will need to be adapted to explain the unique food system problems and to defend the claim that the food system is structurally unjust. Young's theory of responsibility will be employed to explain how participants within the industrial food system must understand their accountability. If the production and consumption of industrial food constitute a manifestation of structural injustice, what are the obligations of the participants in the system, and what hope is there that we may establish a more just food system? 


\section{Individualistic model}

The individualistic model, common in public discourse about the industrial food system, emphasizes human agency, personal liability, and clear causality. According to the individualistic model, the issues stemming from the production and consumption, although unfortunate, result from the actions of individual blameworthy actors. The problems themselves are not connected. After all, the food system is maintained and supported by free-willed human agents, and it is nearly impossible to establish causality between occurrences as disparate as the feeding of a grain-fed steer and the onset of heart disease in a consumer halfway across the nation. Perhaps to suggest that everything is interrelated unnecessarily complicates matters. Problems within the food system are most easily understood at the micro level, where the actions of the consumer are transparent and the causality evident.

The characteristics of the individualistic model become apparent when discussions about various problems within the food system arise. When there are concerns about consumer food choices, the conversation emphasizes the role of individual eating habits and a consumer responsibility for personal health. Structural issues and population health are consistently neglected. The same narrow focus occurs in discussions about the workers within the industrial food system. The hiring of undocumented immigrants and the practices of individual farmers are questioned, but these issues appear to exist independently within the industrial food system, so their structural relevance is ignored. Often, the news media may channel the individualistic model in public discourse. Two problems within the industrial food system, widespread obesity and the administration of antibiotics to food animals, will be examined from this perspective.

With reference to McDonald's offerings, a writer for the Kansas State Collegian notes, “There's no trickery involved here, people” (Ingram). This statement reflects an underlying 
premise of the individualistic model: food choices are straightforward. Or perhaps even: when individuals make poor choices, they must live with the consequences, as the problems are the direct results of their free actions. More than sixty percent of Americans are overweight, and diabetes affects almost 26 million - the majority of whom have acquired the disease as a result of their lifestyle and eating habits (American Diabetes Association). If "nobody in their right mind believes for a second that eating fast food is good for you [...]” (Ingram), how can the obesityvia-fast-food epidemic be explained? That consumers knowingly and willfully make poor choices for their own health is the unfortunate and seemingly logical conclusion. Such an assumption is supported by the controversy in New York City, sparked by Mayor Michael Bloomberg when he supported a ban prohibiting the sale of sugary drinks larger than sixteen ounces. Public protest resulted, presumably because Americans believe in a wide range of free choices, even arguably careless and dangerous ones. This notion of free choice is central to the individualistic model. From an individualistic standpoint, discussions about obesity should focus on the simplicity of food choices and on individual consumer behavior-and irresponsibility.

Is the same individualism and atomism true of the farmers who choose to administer antibiotics to their livestock? Today, the practice is exceedingly common. In February 2013, the Food and Drug Administration released its 2011 report, which disclosed alarming statistics: food animals are currently fed almost 30 million pounds of antibiotics yearly. Although there are undoubtedly more food animals than people in this country, it is noteworthy that Americans themselves consume fewer than 8 million pounds of antibiotics each year (Wallinga). A recent New York Times Article, “Farm Use of Antibiotics Defies Scrutiny,” criticizes the lack of FDA oversight on farms where antibiotics are used and laments the impossibility of policy changes given the dearth of more detailed scientific data. However, the practice of injecting antibiotics 
into livestock is not in itself questioned; the actual points of scrutiny are all of the other ancillary details. Which antibiotics are being used? On which farms, in what amounts, on what animals? The arguably obvious and more pertinent question—why are antibiotics being used at all?—is never posed. From an individualistic perspective, farmers may have the right to make such decisions. If certain practices with regard to antibiotics are deemed to be unduly harmful, the individualistic response would suggest that we punish those farmers who do not comply with the agreed-upon regulations.

If one believes that the industrial food system respects personal choice and freedom, it is likely that one also endorses the notion of personal liability for one's own actions. If the food system is examined from a purely personal perspective, the idea of a violation of free will may be unintelligible. If one could imagine a situation in which an individual's freedom to choose was not respected within the food system, this violation would result from the failings of individuals: an uneducated consumer or a misrepresented product. All people have free choice, and to blame any affliction on society is to try to avoid accountability for one's own actions. Thus, it is the consumer's own fault if he or she chooses to consume unhealthful food and thus suffers from obesity or other health problems. The farmer who uses too many or the wrong kind of antibiotics should be subjected to scrutiny. Such choices are made by individuals, so the liability for any consequence is just that—individual.

Even if the individualistic model can convincingly assert that adults should take responsibility for their own problems, children who participate in the food system represent a unique challenge. Children, impressionable and lacking fully developed rational wills, are the target of approximately $\$ 2$ billion in annual marketing campaigns. (Federal Trade Commission ES-1). Increasingly, toddlers influence the buying decisions of their parents. In her article, 
Freeman notes that "one in five American children now requests particular food brands by age three” (Freeman 2236-7). This early saturation with industrial food suggests that our supposedly natural desires may be more highly manipulated than we realize. Furthermore, children can be used as kinds of marketing “weapons” against their parents. A whining, hungry child may advertise for McDonald's more effectively than any commercial, and the food choices of parents or even a whole family are thus decided by a three-year-old—whose decisions are decided by calculated and extremely effective targeted marketing.

Unfortunately, an emphasis on free choice and the resulting responsibility-for both individual children and adults—obfuscates the pertinent issues the industrial food system. Concerning nutritional deficit and obesity, personal liability fails to take into account the full complexity of the problem. Individual preferences, values, lifestyles, and culture undoubtedly influence how one eats, but other factors that play a role in decision-making should not be underestimated. One should not downplay the social dimension of habit, nor should one fail to consider the way in which the food system encourages a particular kind of diet. The way we eat has become ingrained in our institutions_-and once formed, those norms are resilient. Additionally, level of education and socioeconomic status, which are themselves determined by social structures, play a role in the food system as consumers make choices. Higher education potentially correlates with ease of access to reliable food information, and only socioeconomically privileged individuals have the resources to alter their buying choices, should they decide to do so after becoming adequately informed.

Personal liability is similarly problematic when applied farm use of antibiotics. At the very least, the problem appears to be collective rather than individual: many farmers act in silent accord with each other, insofar as almost all of them inject their livestock with antibiotics. Given 
that the use of antibiotics on farms both increases farmers' expenses and raises concerns about antibiotic-resistant bacteria, farmers should not want to use antibiotics. Surely their use would be easily curbed, then. Yet a veterinarian interviewed by Pollan claims that the discontinuation of antibiotics would negatively affect cattle farmers, almost all of whom rely on confined, cornfed cattle: “We'd have a high death rate and poorer performing cattle. We just couldn't feed them as hard" (cited in Pollan 79). From this Pollan concludes that the entire system would have to slow down without antibiotics, which in effect would generate weaker profits for farmers who already struggle to earn a living (Pollan 79). Clearly antibiotics, although themselves a food system problem, are actually a solution to a different problem—-the liability for which is neither individual nor causally clear.

Advocates of the individualistic model, in keeping with free choice and responsibility, attempt immediately to lay blame when confronted with problems. The blameworthiness results from the individual agency evident in the causal chain of events. Consumers at McDonald's are not threatened or coerced; they individually and of their own free wills drive their cars, stand in line, pay for the food, presumably from their own pockets. There are deeper levels of decisionmaking behind these choices, but the individualistic model ignores this intricate story and assigns liability only to the agent most proximate to the consumption of the food—-the eater herself. With regard to antibiotic use, the application of the personal liability perspective generates a similarly incomplete analysis. It is unlikely that the farmer would be cast as liable at all, because antibiotic use is widely accepted and connections are not drawn between antibiotic use and other problems within the food system. The liability model seeks to identify blameworthy agentsand inevitably fails when it isolates the actor closest to the harm, as proximity to wrongdoing is not necessarily indicative of blameworthiness. The individualistic model focuses on personal 
liability as a result of clear causality, but neither liability nor causality can be accurately established unless the injustice is considered holistically.

\section{Structural model}

A discussion of structures and systems as a whole is requisite prior to engaging with the subject of this thesis. Society is characterized by structures, as human beings tend to form habits and patterns of behavior. Social structures may be ingrained through norms or solidified by means of institutions. Structures are constituent parts of society, so the food system may be understood as part of this country's economic structure. For example, the practices and culture of American grocery stores rely on corporate partners and the buying habits and patterns of millions of consumers. Processes within and interactions of these stores mirror American culture and its underlying economic structure. It may be necessary here to clarify the distinction between structures and systems. Systems are characterized by interconnected processes that accomplish some function, and they may operate within social structures. The terms, while not quite interchangeable, are closely related.

Iris Marion Young claims that "structures denote the confluence of institutional rules and interactive routines, mobilization of resources, as well as physical structures such as buildings and roads” (Young 111). Kenneth Parsons provides a broader understanding; he describes structures as "organized patterns of activity" (Parsons 173). Perhaps the definitions can be merged, resulting in the idea of structures as patterns of human activity that are organized and enabled by social rules, routines, resources, and physical structures. Structures seem to be inevitable features of human societies, and their mere existence does not seem to entail any moral dilemma. Structures, as they exist in themselves, are not necessarily problematic. Of 
moral concern are the undesirable consequences that can result from a structure-a human construct that appears to have surpassed human control as it creates or permits injustice.

One must also be clear about the terminology of the food system. The concept of a food system is not necessarily a new one. Even in America’s not-so-distant agricultural past, there was interaction and cooperation inherent in the task of feeding the society. These earlier individuals participated in kinds of social institutions and benefitted from their participation. The term food system simply denotes a group of individuals, organizations and corporations that interact with or for each other in order to produce, transport, distribute, sell, consume, or otherwise relate to food in a meaningful way. During the last century, a transformation of the means of food production has occurred, but it did not convert a non-system into a system. Instead, an agricultural system became a more highly industrialized one. It is this change that has created, accelerated, or enlarged many of the concerns that are the subject of this paper.

Agriculture is an industry in itself, but the term industrial connotes more than a trade or a means of production. Rather, the industrialization of the food system exists on a continuum. Several drastic changes occurred during the middle of the $20^{\text {th }}$ century, but industrialization had been occurring for many decades prior. The use of tools or technology in the production of food may be one indicator of an increase in industrialization. Industrialization has made the food system more productive than ever before, yet far less efficient in terms of the number of calories yielded per unit of energy input. Between 1940 and 1970, the amount of energy input into the food system increased by almost fivefold. The number of calories produced also increased, but not by the same factor, and many calories were wasted since human consumption in this country could not possibly increase at the same rate. In that same period, the input of human energy-in billions of “man hours” expended on the farm—decreased by approximately 75 percent 
(Steinhart and Steinhart 309-10). Currently, human energy has been almost completely replaced by fossil fuel energy; roughly fifty gallons of oil are now used to plant and harvest a single acre of corn. (Pollan 45) The opacity of the processes within the industrial food system has presented consumers with perturbing new questions: What, exactly, is this food? Where did it come from, and how did it get here? Who made it, and how? Increased industrialization should not be accepted as the innocuous byproduct of technology and modernization. Instead, the industrialized food system should be scrutinized for the uniquely disastrous consequences it poses for society, particularly because structural injustice exists along the complex food chain to which virtually everything consumed in this country is attached.

Because of its weaknesses, the individualistic model is not well-suited for an analysis of the industrial food system. Before the merits of the application of the structural model to the food system can be appreciated, one must have an understanding of structural injustice in general. In "Responsibility and Global Justice,” Iris Marion Young delineates the concept of structural injustice in her examination of global sweatshops. She identifies gross human rights violations in the treatment of the often young, female workers in sweatshops. Employees work in dangerous conditions and are forbidden from using the bathroom or taking breaks; they are forced to work sixteen-hour days or through the night. Abuse and sexual harassment are common, and worker oppression is often supported by anti-union governments. Sweatshops are an example of structural injustice, which "exists when social processes put large categories of persons under a systematic threat of domination or deprivation of the means to develop and exercise their capacities, at the same time as these processes enable others to dominate or have a wide range of opportunities for developing and exercising their capacities” (Young 114). 
Responsibility for such injustice is avoided by the retailers that distribute the apparel, because the retailers do not own or operate the sweatshops. Anti-sweatshop activists protest the buying practices of governments and universities, because the decisions of these particular consumers carry significant weight in the apparel industry. But the prevailing belief is that consumers—-whether individual or institutional—are not to blame, because the guilt supposedly lies with the owners and managers of the sweatshops. Yet sweatshops are manufacturing centers "at the bottom of a chain of specification, distribution, and marketing that often involves hundreds of distinct companies” (Young 108). There is a long chain between the sweatshop worker and the consumer, so no single entity seems to be entirely legally or morally responsible for the "domination, coercion, and need-deprivation" (Young 111) that occur in sweatshops. "Because of the complexity of the system that brings items from production to sale, and the manner in which the system constrains the options of many of the actors within it, this is an example of structural injustice” (Young 111).

A conflict in the distribution of responsibility results from the attempted application of the liability model, defined by Young in a way that is consistent with the previous examination of liability in the individualistic model. The liability model relies on legal reasoning to establish which parties have guilt or fault for some harm; it is assumed that there is a causal relationship between the offender and the person harmed. Young admits that "a concept of responsibility as blame or liability is indispensable for a legal system and for a sense of moral right that respects agents as individuals and expects them to behave in respectful ways toward others” (Young 118). However, a traditional notion of liability, which features in individualistic and atomistic thinking, cannot explain the injustice that occurs in sweatshops-because the injustice is not merely personal, but structural. The "first-line agents of harm," or the owner and managers of 
factories, may be likely candidates for blame under the liability model, but one must consider the relative lack of choices experienced by these individuals. Sweatshops exist in a highly competitive environment, where operators will undercut others who do not minimize costs at every opportunity. Operators face pressure from exporters, who face pressure from purchasers. This intricate global system does not enable good intentions or respect for human rights—-those who try to act morally will be swiftly undersold by their competitors.

In traditional liability thinking, harms must have perpetrators, and individuals alone are blameworthy. In this sense, liable may also signify "legally guilty,” so the laying of blame is not to be taken lightly. However, it is clear from Young's work that individuals who contribute to structural injustice cannot be personally isolated and blamed. Furthermore, even those who know they commit some level of wrongdoing-such as the owners and operators of the sweatshops—are unlikely to admit to and try to correct the injustice, because they fear they will be blamed without consideration for the structural conditions that influenced their involvement. The application of the liability model to structural injustice results in a contradiction: liability presupposes the existence of guilty individuals upon whom we can lay absolute blame. In the absence of such individuals, it is unclear— to a believer of pure liability—how injustice could have resulted at all. Yet it would be illogical to suggest that injustice does not occur in sweatshops—or in the industrial food system. Stripped of the ability to blame personally liable individuals, proponents of the liability model are left with no means by which to identify who or what could be responsible, and to what degree. Because an individualistic notion of liability fails to accurately identify actors who are solely responsible, the structural model is necessary.

Professor Newton Garver and sociologist Johan Galtung — two thinkers whose writings are consistent with Young's theory—clarify the way in which structures can cause serious social 
harms. Newton Garver, writing for The Nation in 1968, explores the idea of quiet, institutional violence. Garver explains that "the institutional form of quiet violence operates when people are deprived of choices in a systematic way by the very manner in which transactions normally take place. It is as real, and as wicked, as the thief with a knife” (Garver). Garver’s definition reinforces the idea that violations of free will and personal choice within the food system should be conceived as structural—or in his words, institutional. The industrial food system operates well, presumably as it was intended by its designers. People eat, the economy grows, and all is well. There are undoubtedly parallels between the deprivations of choice described by Garver and Young's concept of structural injustice.

In 1969, sociologist Johan Galtung introduces the term structural violence, perhaps for the first time. Galtung seeks to explain the indirect kind of violence that occurs via social structures, when the resources and the power to disseminate the resources are unevenly distributed. As opposed to physical or psychological violence, "violence is here defined as the cause of the difference between the potential and the actual, between what could have been and what is” (Galtung 168). Galtung suggests that structural violence may be seen in the reduced life expectancy of certain individuals. For example, in recent years the overall life expectancy for men has increased to approximately 76 years old, but there are stark disparities when the statistics are broken down by race and social class. In particular, Galtung would be interested in the tendency of male members of the lowest-income, black population to die at age 65, compared with the most affluent, white American males who can expect to live until age 80 (Clarke 1376). Insofar as it is structural, this outcome does not result from unjust actions by individual actors, but from a lifetime of choices, or lack thereof, that results in the ultimate deprivation—an 
untimely death. Clearly Galtung's work, too, reinforces the structural component of Young's theory and helps to explain how the food system as a structure can be harmful.

Both Garver’s and Galtung's analyses are beneficial for this exploration, because both works offer a clear example of how unjust structures can result in violations of persons in the absence of ill-intentioned, individual perpetrators: "There may not be any person who directly harms another person in the structure. The violence is built into the structure and shows up as unequal power and consequently as unequal life chances” (Galtung 171). Galtung appeals to the idea of inequity with regard to power and life chances and includes injustice in his argument: "In order not to overwork the word violence we shall sometimes refer to the condition of structural violence as social injustice” (Galtung 171). To return to Young's definition, structural injustice occurs as a result of social processes that deprive some persons of "the means to exercise and develop their capacities" while another group of persons is simultaneously given ample opportunities to do so. Structural injustice occurs when people pursue their own interests, “within given institutional rules and accepted norms” (Young 114).

\section{Application of structural injustice}

The structural injustice model is better equipped to accurately assess both the industrial food system as a whole and the specific problems of obesity and antibiotic use. Although personal choice is relevant to these issues, the individualistic component of these problems will not be acknowledged here, as it is obvious that individuals ultimately take some action that contributes to these problems. Proponents of the structural model do not ignore the importance of personal actions; they simply contend that an account of personal agency offers an incomplete portrayal of the problems within the industrial food system. Assuming that problems exist only 
for particular blameworthy individuals or examining structural problems atomistically oversimplifies the diagnosis. The structural model views problems and responsibility for them holistically. Obesity and antibiotic use have complicated, interrelated causes and effects. Strangely enough, both are related to governmental policies regarding a single crop: corn. According to Michael Pollan, "when food is abundant and cheap, people will eat more of it and get fat” (Pollan 102). Corn has become more abundant and cheaper than most other foods, and Americans consume it in astonishing quantities. A brief historical sketch is required to understanding the prevalence of this crop. After the Second World War, the government needed a plan to dispose of excess ammonium nitrate, which had been used for wartime explosives, and it was decided to use the chemical as fertilizer (Pollan 41). Prior to the advent of synthetic fertilizer, a farmer might have gotten a yield of 70 to 80 bushels of corn per acre; modern farmers can produce almost 200 bushels per acre. Much of this success is attributable to the use of fertilizers (Pollan 37). Farmers began to grow only corn because it was such a profitable crop, and the corn supply quickly surpassed the demand. Despite economic common sense, farmers continue to grow so much corn that it is sold for less than what it cost the farmer to produce it. This practice, albeit illogical, is supported by the government; as many as 5 billion federal dollars subsidize the cheap crop (Pollan 54).

One cannot accurately evaluate the obesity epidemic in this country without considering the role of corn and its derivative, high-fructose corn syrup. Obesity undoubtedly results from a number of factors, but at least some of our collective weight gain can be ascribed to the extra 200 daily calories we consume, on average, in comparison with American consumers forty years ago (Pollan 102). Many of these calories may have their source in high-fructose corn syrup, or HFCS, a food industry invention of the 1970s. Approximately 17.5 billion pounds are produced 
annually in an attempt by the food industry to remedy this country's massive excess of corn. The average person consumes 66 pounds of HFCS annually, partially attributable to the large amounts of HFCS commonly found in soft drinks. The volume-per-container of these drinks has also been increasing by means of creative marketing in the past few decades, which induces Americans to drink even more HFCS. (Recall the New York City legislation preventing this very tendency in consumers).

The implications of HFCS for obesity are quite serious. Human beings are evolutionarily inclined to prefer energy-dense foods—-those that are high in sugar and fat. However, this biological adaptation is no longer a fruitful survival technique; we are surrounded by food, but our bodies continue to crave those that will inevitably fatten us. Even worse, the refined, highly processed HFCS contains sugar in unnatural proportions, and the human metabolism is not designed to handle such a substance. Although consumers do exercise some agency in choosing to purchase sugary beverages, HFCS has surreptitiously made its way into all sorts of unlikely products. Pollan notes that one can even find it in ketchup and crackers (Pollan 106-7). Clearly, the obesity problem is not merely a failing of responsible personal choice. Consumers had never desired or ingested HFCS until the substance was introduced and supported by institutions. Decades of farm policies have resulted in an excess of corn; the government and various corporations want to dispose of this excess. They may conveniently do so in the consumer's stomach—previously believed to be inelastic—and glean healthy revenues in the process (Pollan 106).

Many of the same background issues apply to the consumption of fattening, corn-fed beef-a novelty that Americans now consume much more frequently than grass-fed beef. Beginning in the 1950s and 60s, the excess of corn that resulted from government policies 
encouraged farmers to feed the corn to their livestock, since the grain was cheap and readily available (Pollan 39). Cattle were now able to be brought to slaughter weight in just over a year, whereas traditional grass-fed cattle required between two and three years (Pollan 71). Meat from corn-fed cows is "marbled" with fat, and its saturated fat content is much higher than that of grass-fed cattle. Its increased fattiness, combined with its new cheapness derivative of the cheapness of corn, has resulted in consumers who eat greater quantities of markedly unhealthier beef (Pollan 75). There is surely a connection to obesity here; personal choice is again relevant, but the unique circumstances of beef in this country result from government and farm policies which are rarely scrutinized or even known by the average consumer.

The use of antibiotics on factory farms is also related to corn. The "benefits" of raising cattle on a corn diet, as well as the cheapness and availability of corn, has spurred the creation of concentrated animal feeding operations (CAFOs) where corn is the feed of choice. However, cows are ruminants; they are biologically designed to consume grass (Pollan 70). Serious medical conditions, including bloat and liver disease, can result in cattle when they are raised on a "feedlot diet." The majority of animals on CAFOs are sick. Rather than switch to an appropriate diet, however, most farmers administer large quantities of antibiotics— both to remedy corn-induced sickness and to promote fast growth (Pollan 78-9). This “solution” is costly for the rest of society, considering the increased prevalence of antibiotic-resistant bacteria. But it allows cattle to survive until slaughter, which is of primary importance to the farmer. However, the farmer would have likely never chosen to administer antibiotics on his or her own; the practice results from the excess of corn and the commercial pressure on farmers to grow cattle as quickly as possible on a corn diet. 
The increased productivity demands on modern farms may be explained by several historical developments. In 1935, there were almost 7 million farms in this country, and farms with more than 500 acres represented only 4 percent of all farms. By 1997, there were fewer than 2 million farms, and the number of 500-acre or greater farms had increased to represent 18 percent of all farms (United States Department of Agriculture). In general, farms are fewer and larger, and some beef operations are growing in size. In Nebraska, the location of many large cattle feedlots, the largest beef producer is currently home to 85,000 head of cattle, and almost 800 producers in the state are authorized to have more than 1,000 head of cattle (Singer 63). The logic behind such expansive "food animal cities" is confirmed by their supposed efficiency; CAFOs have made meat cheaper than ever before (Pollan 67). Because there are fewer farmers and more cattle per farm, farms must become more productive. To keep prices low, grassfeeding and natural growth are abandoned. Corn-fed cattle become cogs in the machine that is the industrial farm, and quicker turnover—in less elegant terms, quicker slaughter—means quicker profits. Antibiotics are just another input required to keep the system functioning.

Thus, both obesity and antibiotic use and the responsibility for them cannot be comprehended if they are understood as merely individual. Human agents are responsible, to some extent, for their own actions; the structural injustice model simply suggests that the individuals nearest to the wrongdoing itself are not the only significant actors. Therefore, the consumer of fast food and the farmer who uses antibiotics are not the only blameworthy parties. In both cases, scientific "progress" and governmental subsidies of corn have created problems that never existed organically. Therefore, it is likely that neither the consumers nor the farmers have a clear idea of how to remedy their respective unfortunate situations. Their individual actions did not independently create their problematic situations; both obesity and antibiotic use 
surpass the realm of the individual. Yet the structural injustice model does not equate to exoneration of individual actors; the structural model is rather the adjustment of a flawed and biased lens, with the hope of correcting the unfairness evident in the food system.

In the industrial food system, those who suffer from the structural injustice are not as easily identifiable as the oppressed workers in Young's sweatshop example. Moreover, the concept applies in different ways to both workers with the food system and to consumers who depend on its production. The structural injustice that both workers and consumers experience is the deprivation of the means to exercise their capacities—capacities which presumably include free, rational wills. The system, in all its complexity, constrains the choices of both those who work within it and those who participate in it by means of their purchases. Workers in particular experience another harm described in Young's structural injustice model: the systematic threat of domination. They seemingly work within the food system at will, but various kinds of manipulation are relevant. On the other hand, consumers have a dualistic relationship with the structural injustice of the food system, an interaction that was never explored in Young's examination of sweatshops. Consumers simultaneously contribute to the structural injustice by means of their purchases and harm themselves, both as a result of the quality of the food they consume and the environmental degradation that results from its production. Persons who experience structural injustice in distinct ways will be grouped together, as workers and consumers, and will be analyzed separately.

\section{Workers}

This thesis will focus on three types of workers: farmers, agricultural workers who labor in the fields, and slaughterhouse employees. Economic constraint may be a factor in the 
decision-making by many individuals who work in the food industry, but the structural injustice manifests itself differently with regard to each of the populations. Farmers within the industrial food system must contend with giant agricultural corporations and with governmental farm policies. Often, farmers face economic pressure and manipulation as a result of these interactions. Agricultural and slaughterhouse employees may face systematic abuses of their rights as workers, as they deal with low wages and horrific working conditions. Many of the violations of free choice and other capacities in both employment roles, however, result from the unique design of the American industrial food system and exemplify structural injustice.

First, the deprivation experienced by the shrinking population of American farmers will be examined. Today, most farmers own neither the seeds they plant nor the livestock they raise. The lack of ownership on farms creates structural injustice, as the farmer loses his ability and right to conduct his own business as he sees fit. There may be some parallel between farmers and sweatshop owners as described in Young's argument: farmers have relatively little control of the farm's operation, and their economic need encourages their employment in the suboptimal system. Currently less than 20 cents of each consumer's dollars makes its way back to the farm that produced the food; the remaining 80 cents pays for the marketing of the food product (United States Department of Agriculture 21). Thus, these conditions signify that the average farmer lacks the ability to improve his or her situation; the alternative is continued participation in the structurally unjust food system.

The agricultural giant Monsanto controls many of the operations on a seemingly independent industrial farm. Farmers enter into contracts with Monsanto in order to receive the company’s genetically modified, high-yield seeds. High-yield crops appeal to farmers, of course, not least of all because of traditionally low selling prices of crops and governmental 
policies that effectively increase supply and diminish demand. Additionally, because many farms are single-crop operations where artificial fertilizers are used, the soil lacks the necessary fertility to ward off pests (Pollan 148). As a result, Monsanto's seeds are particularly attractive, because they have been biologically engineered to be resistant to pesticides-the chemicals that have become necessary in order for monoculture crops to grow (Pollan 221). The seeds are intellectual property, protected by patents, and Monsanto then dictates what farmers can and cannot do on their farms (Center for Food Safety). Monsanto forbids the saving of seeds at the end of a season, so farmers must pay Monsanto each year for their technologically advanced product. Farmers who try to circumvent this transaction end up in controversial lawsuits, the most recent of which has been escalated to the Supreme Court (Parry).

With regard to livestock, poultry operations clearly demonstrate the power of corporations and relative powerlessness of the farmer. Tyson Foods, the world's largest chicken processor, has ownership over significant aspects of poultry production on industrial farms; Tyson owns the chicks and thus mandates the conditions of their growth. Farmers are often in debt as a result of their relationships with the processors, since the farmers themselves must assume "the capital expenditures and the financial risks" of raising the chickens (Schlosser 140). The individual farmer provides the land, the manpower, the house for the chickens, and the fuel to run the operation. Farmers must increase their rate of growth to compensate for their expenses, and contracts with processors are often prerequisites for bank loans (Schlosser 141). These agreements with processors, which are kept confidential, have previously forbidden farmers from suing the processor and from forming associations with other growers (Schlosser 141-2). Needless to say, this restrictive environment with respect to both seeds and livestock 
significantly restricts the choices of farmers, and the deprivation of their free wills is a kind of structural injustice that enables other violations within the food system.

Low-income, migrant agricultural employees suffer from more pronounced instances of structural injustice. They are some of the food system's most unfortunate employees, since their situations are dictated by the demands of the system and by the pressure experienced by their employers to produce food at an absolutely minimal cost. Some farm workers earn as little as $\$ 3,500$ annually, and they rarely have access to job benefits such as overtime pay or health insurance. Some members of these populations may not speak fluent English and thus cannot communicate with their employers about fair working conditions and reasonable expectations on the job. These particular workers are also likely unfamiliar with American laws and workers' rights, and it is possible that their economic needs outweigh some of their other concerns regarding their safety and wellbeing on the job. They may fear retaliation if they express discontent with their employers and if they are undocumented, their employers may retaliate by threatening deportation or by reporting the individual to the authorities (Southern Poverty Law Center). Although farm workers are to some degree responsible for supporting a crucial component of the industrial food system, they are also victims of its structural injustice because of their inability to otherwise develop their capacities.

In the slaughterhouses, workers do not fare better. These employees have the most dangerous jobs in the industry, and much of their plight is unknown or otherwise ignored by the general public. Their deprivations, too, are determined by the unjust structure that exerts undue pressure on its employees. Author Eric Schlosser tours a meatpacking plant for the purposes of his book, and he notes that the majority of the workers are young, Latina women. As in the fields, underprivileged workers in slaughterhouses often fear retaliation by their employers and 
thus accept the abuses of the job and fail to report injuries (Schlosser 175). Upon observing working conditions he finds that "the injury rate in a slaughterhouse is about three times higher than the rate in a typical American factory. Every year more than one-quarter of the meatpacking workers in this country — roughly forty thousand men and women—suffer an injury or a work-related illness that requires medical attention beyond first aid” (Schlosser 172). The speed of the disassembly line is the leading determinant of injury rate, so it would seem logical to slow the process in order to reduce workplace accidents (Schlosser 173).

Yet the speed of the disassembly line is invariably linked with earnings, and a slaughterhouse that invests in worker safety will be underbid by competitors who tolerate higher injury rates in favor of efficiency and subsequent profits. Organizations such as workers' unions and the Occupational Safety and Health Administration (OSHA) would presumably object to the disregard for worker safety in slaughterhouses, but neither group is equipped to address the systemic problem. In the case of IBP, one of this country's three meatpacking giants, only onethird of its employee population is unionized, and the line speeds and labor costs are determined by the nonunion plants (Schlosser 174). Therefore, unions in the meatpacking industry lack the ability to advocate for better conditions. OSHA is similarly powerless. Approximately 1000 OSHA employees are responsible for monitoring 5 million workplaces across the country, and OSHA accepted the policy of "voluntary compliance” in the 1980s. OSHA inspectors no longer arrive at slaughterhouses unannounced; they inspect the company-maintained injury logs and only examine those sites with above-average injury rates (Schlosser 179). Consequently, slaughterhouses are further incentivized to misrepresent the occurrence of workplace accidents. The structural design of this system, not entirely unlike that of sweatshops, deprives employees of their right to a safe and fair workplace in the interest of profitability. 
Both farmers and other workers within the industrial food system experience structural injustice. Their employment maintains the system, but they often do not have the opportunity to better their own situations; they are deprived of this capacity by the demands of the complex structure within which they work. Members of the three groups experience a loss of the sense of control in their jobs, and agricultural workers and slaughterhouse employees in particular suffer workers' rights abuses. This injustice occurs as a result of the actions of all participants in the industrial food system: corporations and the government play a role with their policies, but everyday consumers are responsible as well, insofar as they participate in the structure. Workers within the industrial food system may be the most obvious examples of sufferers of structural injustice, but the constraint experienced by consumers in their decision-making demonstrates that consumers too, experience a deprivation of the means to develop their capacities.

\section{Consumers}

Consumers are an unusual case for this examination of the industrial food system, considering that Iris Marion Young's views of structural injustice are heavily influential. It must be noted that Young's argument does not specifically address a similarly exceptional case. In sweatshops across the world, the workers experience the structural injustice, and the consumers perpetuate it. Yet the concept of structural injustice is so applicable that it can accurately assess the situations of both workers and consumers, although they are at opposite ends of the production-consumption chain —an advantage that even Young did not explore. In the case of food, consumers reinforce the unjust system with their purchases. However, the structural injustice also harms the consumers in at least two ways. The manipulation of food choices and the promotion of nutritionally deficient options have worsened consumers’ health, and 
everyone-regardless of their choices—experiences the environmental consequences of the means of food production. Consumers should not be cast as helpless victims, since their agency is involved to some degree, nor should they be held entirely responsible on a personal level, per the individualistic model. Rather, the structural injustice model provides a fruitful analysis.

In the earlier discussion of the structural causes of obesity, our biological predisposition to prefer certain foods was mentioned. However, only high-fructose corn syrup was scrutinized for its opportunistic invention and subsequent inclusion in the American diet. Unfortunately, an entire industry is dedicated to manipulating the human stomach and engineering food so that eaters constantly crave and consume more. In a recent New York Times article, writer Michael Moss claims: "It's not just a matter of poor willpower on the part of the consumer and a give-thepeople-what-they-want attitude on the part of the food manufacturers." Instead, there is a conscious but surreptitious mission to addict consumers to convenient, inexpensive foods (Moss). The food industry employs psychologists to ensure "product optimization" through extensive testing; scientists have already discovered our "bliss point," or optimal level of sensory experience. Our addiction also may be attributed to the presentation and convenience of food: Lunchables were wildly successful because of the independence they signified to children. And, of course, because of the sugar, salt, and fat of which they were made (Moss).

In 1999, when the CEOs of some of the biggest corporations in the food industry met to discuss “the obesity problem," General Mills' CEO Stephen Sanger perfectly characterized the real problem in his refusal to address it. According to Sanger, consumers did not want to think about nutrition; they bought products that tasted good, those high in sugar, salt, and fat. To respond to critics concerned about obesity would require the food industry to change its unhealthful recipes, to which it owes its success (Moss). There seems to be no question that an 
abandonment of sugary cereal in favor of carrot sticks signals economic suicide in the industry; even CEOs with the best intentions are not willing to make such an illogical, self-destructive decision. Yet top executives in the food industry wring their hands when the conversation turns to obesity, for food manufacturers dread the moment in which they will be compared to the cigarette industry. It seems that eating has indeed arrived at an equal level of vice, and fingers point back to the creators of such unethical food: individuals acting in their accepted institutional roles, in accord with the expectations of the industry.

In addition to the food industry's inexorable profit-driven pursuit and manipulation of the consumer's preferences, it even dismisses its own employees when they develop scruples. Jeffrey Dunn, who in 2001 was president of a $\$ 20$ billion Coca-Cola enterprise, serves as a perfect example of someone who was reformed - and then rejected. Coca-Cola's goal was to “drive more ounces into more bodies more often," but Dunn changed his perspective when he was sent to market his product in impoverished neighborhoods in Brazil. After witnessing firsthand that true human need cannot be met by a sugary drink in a metal can, Dunn returned to America and called for the removal of Coca-Cola marketing in public schools. Shortly after, Dunn was fired. In many cases, however, industry executives may not challenge the status quo, for they know their jobs are at risk. They have a sense of the wrongness of their actions and of those of the industry, but they feel powerless to change them. This deprivation of free will speaks to the structural nature of this problem, for there are agents who knowingly support an unjust institution. The structure of the food system does not allow for those who act in the best interests of the consumer's health. Rather, it is designed so that Americans consume as much sugar, salt and fat as humanly possible—and then crave some more (Moss). 
In “Fast Food: Oppression Through Poor Nutrition,” Andrea Freeman examines how "targeted marketing, infiltration into schools, government subsidies, and federal food policy" play a role — especially in low-income, urban, minority communities—in the denial of healthy food choices. Freeman describes the situation in West Oakland, California, where 30,000 primarily African American and Hispanic residents are served by a single grocery store (Freeman 2221-2). The prevalence of fast food restaurants, in combination with the relatively high prices of other food vendors, lack of private transportation, and convenience, encourages consumers to purchase fast food regularly. There tend to be socioeconomic patterns among factors that influence this decision; time is an especially important consideration among lowincome populations. For individuals who work long hours or multiple jobs, time is a precious resource that does not seem best spent finding transportation to a grocery store, shopping, and returning home to cook. In this way, fast food fulfills a need, although in a suboptimal way.

Unfortunately, fast food companies similarly address a shortage within some low-income school districts. Impoverished schools contract with corporations, sometimes fast food companies, to cover the costs of technology and other expenses. In exchange, fast food companies are permitted to display their logos in schools and sometimes even serve their food in school cafeterias. Shockingly, this food is not subject to the minimum nutrition standards of the National School Lunch program (Freeman 2234-5). This encroachment of fast food companies deprives schoolchildren of healthy eating options and contributes to childhood obesity, an already rampant epidemic. Perhaps it appears as though school officials are to blame, but the permission they grant to the fast food companies results from a lack of other options. Schools need funds to function, so the acquisition of technology and the establishment of extracurricular activities may justify the availability of McDonald's fries in the cafeteria. Yet this trend is 
frightening, for children are a group particularly susceptible to deprivations of the means to develop their capacities. Fast food companies take advantage of children who live in poverty, since the structural features of low-income communities provide little resistance to a corporation intent on increased consumption at any cost.

The above issues concern primarily low-income consumers of industrial food. Even if the more privileged consumer can "opt out" of the food system entirely, many consequences of industrial food will invariably persist as a result of the structural conditions that cause them—the participation of an individual is not necessary, so long as there are hundreds of millions of consumers who continue to do so. The structure will remain unchanged, and all members of society will be negatively affected by the most widespread structural injustices of the system. For example, as long as the current policies remain in place, even uninvolved consumers will be at risk for contracting an antibiotic-resistant infection, which is a concern that arises from the use of antibiotics in food animals. All will inevitably suffer the effects of the environmental ruin that occurs in the name of industrial food, including water contamination from fertilizer runoff, deforestation, degradation of the soil on monoculture farms, and animal waste management. Each of these problems is related to a government policy or the increased industrialization of the food industry, which is supported nationally, regardless of individual preference. Clearly, individual actions alone are insufficient to address a straightforwardly structural problem.

One might object to the idea of restrictive choice as a deprivation of the means to develop one's capacities within the food system; it seems as though American consumers today have more choices than any previous generation. Yet "more choices" must not be conflated with "the appearance of more choices.” It is true that today's consumer has a staggering variety of options, but these should not be confused with choices. For example, although the average American 
supermarket sells 45,000 items, more than 11,000 of them contain corn (Pollan 19). Although they may be disguised by means of complicated ingredient names, corn and its derivatives are the primary ingredients in many foodstuffs, so consumers today are actually influenced by the illusion of choice. Many food purchases actually consist of corn in different forms; it may be found in hot sauce, canned fruit, and even vitamins (Pollan 19). Consumers are likely influenced by marketing that does not emphasize the true nature of products and by federal subsidies that make corn products artificially cheap.

Thus a sheer increase in choices, whether real or perceived, does not speak to the quality of those choices (or if they are illusory, options) and the resulting soundness of those decisions. Among them, are there ones that are healthy for the consumer, the consumer's children, society, the planet? An individual who can choose between McDonald's, Arby's, and Taco Bell is not presented with meaningful choices, because the sources of all of these brands of fast food are nearly identical and demonstrate the same structural problems. Furthermore, it would seem that the consumer must be properly informed about his or her choices in order to determine if any meaningful differences exist between them. Unfortunately, the prevalence of fast food and the industry’s entanglement with federal corn policy, CAFOs, and other problematic institutions within the food system restrict food decisions. Consumers themselves may experience their own choices as "free," but the complexity of the system that feeds them and the constraints that exist even without their knowledge indicate structural injustice.

\section{Our responsibility}

The problems of the industrial food system must be considered holistically in order to accurately portray and diagnose the system and people who accept—or perhaps elude- 
responsibility for its problems. If responsibility is unidentified or misplaced, there is little hope that practical and effective solutions may be found. The problems with production and consumption are widespread, complicated, and interrelated. They result from the actions of so many nameless, faceless individuals; causal relationships are unclear. It seems impossible to distribute responsibility for structural injustice according to a liability model, which is arguably the model our individualistic, atomistic society employs. This impasse perhaps explains the moral confusion that has halted understanding of the food system, its problems, its "guilty" participants, and the appropriate response, retributive or otherwise. Yet, in the face of our hesitation, the numerous problems continue and worsen. If the issues within industrial food are accepted as relevant and pressing concerns for society, we have a duty to move beyond what are perhaps the wrong questions and discover true responsibility.

Injustice that is structural, as described above, calls for new ideas about moral responsibility. Iris Marion Young presents an innovative model of responsibility, one that addresses moral obligations with regard to social problems viewed from a structural injustice perspective. An application of Young's Social Connection Model, or SCM, suggests thoughtprovoking solutions to the Sisyphean problems within the industrial food system. It is important to note that Young's understanding of responsibility involves little or no focus on personal liability, in a pejorative sense; it does not emphasize personal blame. There should be no shame or guilt involved, but rather a desire to correct an injustice from which one may have previously benefitted (Young).

Young identifies five specific characteristics of the SCM of responsibility that distinguish it from the traditional blame or liability model. First, the SCM is unique in that it does not isolate responsibility. Structural injustice may often involve thousands or millions of 
perpetrators, so the wrongdoing is not purely individual. It is neither feasible nor effective to assign individual guilt and punish accordingly. The second feature of Young's SCM is that it assesses "background conditions" (Young 120). These conditions might include social norms and institutional practices that, although widely accepted, allow for the structural injustices that occur in the foreground. Thirdly, the SCM differs from a liability model in its temporal focus. According to Young, "application of the liability model is primarily backward-looking. The social connection model, in contrast, emphasizes forward-looking issues” (Young 121). Backward-looking liability seeks retribution for the past actions of guilty actors, but these individuals cannot be identified when the harm is structural. Additionally, structural injustices are typically ongoing, so forward-looking approaches provide more effective solutions. As a fourth feature, Young identifies the notion of shared or distributed responsibility. Society as a whole is responsible, but each member is responsible personally for his or her participation in the society that produced the injustice (Young 122). Finally, Young claims that the SCM requires collective action. Because the problems result from the actions of many unknowingly coordinated agents, it seems logical to suggest that the solution would likewise require concerted effort by many members in society — who, in the corrective stage, will need to gain awareness of each other and of the consequences of unjust social structures composed of and supported by groups of strangers. For these reasons, the liability model should be rejected in favor of the SCM, which is uniquely suited to explain our responsibility for structural injustice.

Each of these facets of the SCM has an integral application for the diagnosis of the industrial food system as a manifestation of structural injustice. Responsibility within the food system cannot be accurately identified and isolated, partially because of the sheer number of participants. However, this allocation of responsibility is not required by the food system when 
understood as structural injustice. Rather, the study of industrial food should allow one to realize that, because the bulk of consumers are responsible to some small degree, there is an illusion of innocence. Moreover, the farmers and other food industry employees cannot be isolated or blamed individually. The latent understanding that all are partially responsible has somehow transformed into the false belief that no one is responsible. This moral confusion and avoidance of guilt has allowed the structural injustice of the industrial food system to progress, but the SCM frames responsibility in a way that could shed light on these illusions.

Through the SCM, the examination of the background conditions of industrial food would direct responsible agents to question the “accepted norms and institutional practices” that have enabled the structural injustice of the food system to occur. These background conditions would include many governmental policies, including the federal subsidy of corn, which have created or reinforced structural injustice. Various organizations—such as the USDA—and corporations — including virtually all restaurants, particularly the fast food variety—would be analyzed for their contributions to the problems. Other background conditions include habits and assumptions made by consumers and other participants in the industrial food system: a wide variety of food should be available at a certain cost in certain types of stores. Understandably, these institutions may be resistant to change, but it is of paramount importance to consider their relevance, especially considering the misguided focus exclusively on the individual and neglect of contributing factors.

The forward-looking component of the SCM would guide consumers to correct the problems for the sake of the future of the food system rather than apportion blame for the wrongdoing of the past. Even if the guilt of certain individuals or corporations could be proven and penalized, it is unlikely that their retroactive punishment would affect the ongoing structural 
injustice. Historical context may be necessary to fully understand the injustice, but the SCM is concerned with the reparation of the present and the future. The backward-looking solutions that are employed have already proven to be ineffective. For example, USDA policy allows farmers to irradiate beef out of concern for bacterial contamination of the meat, which occurs as a function of the feedlot diet and the conditions within slaughterhouses. When this process is unsuccessful, tainted meat is recalled, a tedious and expensive process. In the interim, consumers are exposed to potentially life-threatening meat. Recalls, which exemplify backwardlooking solutions, necessarily fail to address the unnecessary conditions that will continue to allow tainted meat to be distributed and consumed at a higher-than-acceptable rate. A forwardlooking approach would emphasize the need to prevent the contamination of meat at its source for the sake of future consumers.

The concept of shared responsibility must be accepted for the SCM to be applicable to industrial food. Some agents may be responsible to a greater degree than others, but the SCM does not concentrate on the distribution of blame. According to Young, "each individual is personally responsible for outcomes in a partial way, since he or she alone does not produce the outcomes; the specific part that each person plays in producing the outcome cannot be isolated and identified, however, and thus the responsibility is essentially shared” (Young 122). In the food system, it is virtually impossible to isolate or quantify the contributions of the government, corporations, growers, distributors, retailers, and eaters. We must simply accept that members of all of these groups share responsibility for the injustices perpetuated by the industrial food system. Ideally, shared responsibility would not carry the stigma or legal reprisal associated with the liability model; participants would freely admit the impact of their actions, an acknowledgement that is a precondition for the creation of a just national food system. 
Finally, collective action will be necessary to create meaningful change within the industrial food system. Some individuals have sufficient resources to "exit" from the food system — that is, to bypass all traditional methods of purchase and consumption of food. One may exit by growing all of one’s own food and raising one’s own livestock. However, this option is neither possible nor practical for many Americans. The difficulty, then, is to continue to participate in the system while objecting to its injustices. Industrial food must be changed from within —all the while it is supported by hundreds of millions of consumers. Governmental agencies and for-profit corporations that support or exist for the purpose of industrial food will need substantial—most likely, economic_-motivation to change their practices within the food system. Consumers most often express their approval or lack thereof with their dollar, so informed purchases may be one of the strongest means of influencing the governing institutions.

\section{Final thoughts}

Simply put, the industrial food system is one of the most problematic institutions in this country. Often, it is one of the most misunderstood. The exploration undertaken is this paper is surely insufficient to grasp the full intricacy of the food system and its issues. At a minimum, it is hoped that analysis of food production via the individualistic model will be abandoned. An examination that employs the structural injustice model may allow us to understand the problems and enact desirable change. Once this concept is accepted, the creation of a structurally just food system should be the objective of concerned citizens. Structural justice exists on a continuum, however, and the ideal system will not be achieved. Nonetheless, the current food system is far from utopic, so there is no excuse for complacency. To borrow from John Rawls: "Justice is the first virtue of social institutions, as truth is of systems of thought. A theory however elegant and 
economical must be rejected or revised if it is untrue; likewise laws and institutions no matter how efficient and well-arranged must be reformed or abolished if they are unjust” (3). Let us reject, then, this system, however efficient or well-arranged, for although it does provide us with sustenance, it robs from us elements of life that are far too precious: the health deserved by our children, the welfare bestowed by our environment, and the dignity afforded by our rationality. 
Works Cited

American Diabetes Association. Diabetes Statistics. n.d. Web. 25 February 2013.

Bufacchi, Vittorio, ed. Violence: A Philosophical Anthology. New York: Palgrave Macmillan, 2009. Print.

Center for Food Safety. "Monsanto vs. U.S. Farmers." 2005. Web. 27 Feb. 2013.

Clarke, Christina A, et al. "Racial and social class gradients in life expectancy in contemporary California." Social Science \& Medicine (2010): 1373-1380. Web. 27 Feb. 2013.

Federal Trade Commission. "A Review of Food Marketing to Children and Adolescents." Follow-Up Report. 2012. Web. 27 Feb. 2013.

Freeman, Andrea. "Fast Food: Oppression Through Poor Nutrition." California Law Review (2007): 2221-2259. Web. 5 Sept. 2012.

Galtung, Johan. "Violence, Peace, and Peace Research." Journal of Peace Research (1969): 167191. Web. 17 Dec. 2012.

Garver, Newton. "What Violence Is." The Nation 24 June 1968. Web. 3 Jan. 2013.

Ingram, Karen. "Choices in diet cause obesity, not fast food." Kansas State Collegian 18 January 2011: 2. Web via UWIRE. 25 Feb. 2013.

Wallinga, David. "Animal Antibiotic Use Continues Upwards, FDA Keeps Blinders on." 12 February 2013. Web. 25 Feb. 2013.

Moss, Michael. "The Extraordinary Science of Addictive Junk Food." The New York Times 20 Feb. 2013. Web. 28 Feb. 2013.

Parry, Wynne. "Monsanto v. The Farmer: Supreme Court Hears GM Soybean Case." 25 February 2013. Web. 28 Feb. 2013. 
Parsons, Kenneth A. "Structural Violence and Power." Peace Review: A Journal of Social Justice (n.d.): 173-181. Web. 17 Dec. 2012.

Pollan, Michael. The Omnivore's Dilemma. New York: Penguin, 2006. Print.

Rawls, John. A Theory of Justice. Cambridge: Harvard University Press, 1999. Print.

Schlosser, Eric. Fast Food Nation. New York: Harper Perennial, 2002. Print.

Singer, Peter and Mason, Jim. The Ethics of What We Eat: Why Our Food Choices Matter. Rodale, 2006. Print.

Southern Poverty Law Center. "Migrant Tomato Workers Face Chronic Abuses." 15 April 2008. Web. 20 Feb. 2013.

Steinhart, John S and Carol E Steinhart. "Energy Use in the U.S. Food System." Science (1974): 307-316. Web. 26 Dec. 2012.

United Nations. The Universal Declaration of Human Rights. n.d. Web. 9 Jan. 2013.

United States Department of Agriculture. Agriculture Fact Book 2001-2002. The Delano Max Wealth Institute, LLC, 2011. Web. 24 Feb. 2013.

Young, Iris Marion. "Responsibility and Global Justice: A Social Connection Model." Social Philosophy and Policy (2006): 102-130. Web. 17 Aug. 2012. 